\title{
Intrapleural Administration of Fibrinolytic Enzymes as an Adjunct Therapy of Parapneumonic Purulent Pleural Exudation: Does it Affect Outcome?
}

\author{
Ahmed Saber, MD, FRCS ${ }^{*}$ and Waleed Adel, MD \\ Cairo University, Cairo, Egypt
}

\begin{abstract}
Objectives: To clarify therapeutic effectiveness of intrapleurally-administered fibrinolytic enzymes (Purified Streptokinase).

Methods: In this comparable study, sixty patients were studied between March 2016 to November 2018. All of them were diagnosed having parapneumonic purulent pleural exudation (defined by the presence of purulent pleural effusion or pleural fluid with a pH below 7.2 associated with signs of chest infection and/or proven bacterial invasion of the pleural space). All of them were subjected to proper thoracostomy tube drainage with antibiotic coverage. Patients were divided into 2 groups. Patient selection was according to certain inclusion criteria for each group category. Group A (50\% of patients) were offered the intrapleural administration of fibrinolytic therapy in which 250,000 IU streptokinase over 100 $\mathrm{ml}$ normal saline was injected intrapleurally via the thoracostomy tube (once daily through six days duration) which then was clamped after each session for eight hours asking the patient to change his position keeping close eye on him, then it was opened. Group B patients were offered conventional open surgical evacuation of purulent exudate and decortication. Outcome endpoints between the two groups were compared; namely resolution of pleural exudation radiologically, relief of symptoms and subsidence of signs of chest infection, total duration of hospital stay (since selected procedure done until discharge from thoracic surgery point of view), mortality and/or other complications, and recurrence of the same condition at the same side within sixty days follow-up duration.
\end{abstract}

Results: Patients offered conventional open surgical evacuation of purulent exudate and decortication shows considerably significant values regarding the traced outcome endpoints compared to those who experienced streptokinase injections intrapleurally. Moreover, streptokinase injection causes air leak (3.33\%), intrapleural haemorrhage (3.33\%) and fever $(6.66 \%)$ in our patient group. However, no deaths were met in either group of patients.

Conclusion: Early surgical management of parapneumonic purulent exudation is found to have more favourable outcome. Intrapleural administration of fibrinolytic enzymes is found to have longer period of hospital admission, relief of symptoms and subsidence of signs of chest infection, resolution of pleural exudation, and carry higher risk of complications. However, it does not affect mortality.

\section{Keywords}

Fibrinolytic enzymes, Parapneumonic purulent pleural exudation, Streptokinase

\section{Introduction}

Pulmonary infections with secondary pleural involvement lead to considerable morbidity and even mortality [1-3]. Bacterial and white cell metabolism can rapidly turn a simple exudative parapneumonic effusion into a multiloculated purulentempyemawith lowpHand highlactate dehydrogenase levels. This progressive process involves alterations in fibrin turnover, which leads to the formation of fibrinous deposits and membranes with sequestration of infected fluid $[4,5]$. Accepted management consists of systemic antibiotics and drainage of the pleural cavity, which is achieved by either medical chest tube drainage or surgery. Open thoracotomy or video-assisted thoracoscopic surgery (VATS) achieve the best drainage in gross empyema or loculated effusions, but are limited by operative risk, cost, and local availability [6].

*Corresponding author: Ahmed Saber, MD, FRCS, Cairo University, Cairo, Egypt

Accepted: April 23, 2019

Published online: April 25, 2019

Citation: Saber A, Adel W (2019) Intrapleural Administration of Fibrinolytic Enzymes as an Adjunct Therapy of Parapneumonic Purulent Pleural Exudation: Does it Affect Outcome?. J Cardiothorac Surg Ther 3(1):24-30 
Intrapleural instillation of fibrinolytic agents is undertaken to dissolve fibrinous clots and membranes, to prevent fluid sequestration, and hence to improve drainage [7]. Numerous case series and a few controlled trials have since shown that urokinase or streptokinase (SK) used intrapleurally is safe, increase fluid drainage, and improve some clinical and radiologic outcome parameters [8-16]. However, no controlled trial study addressed treatment success expressed as need for surgery, which is the outcome measure of primary interest for the clinician. Furthermore, it has never been evaluated whether better clearance of fibrinous material translates into quicker recovery of chest mechanics and better long-term functional outcome [11].

Intrapleural instillation of streptokinase was first described by Tillet and Sherry [7]. Its use did not gain acceptance, however, because of the rare occurrence of intrapleural haemorrhage and systemic fibrinolysis $[17,18]$. Such therapy is intended to lyse the fibrinous septations within infected pleural-fluid collections and is supported by management guidelines $[19,20]$. Small trials [21] and case series have suggested that these agents improve drainage of pleural fluid, as quantified radiographically, and may also reduce the need for surgery [22], with few adverse effects. These studies have had low statistical power, however, and have therefore been unable to assess accurately whether these benefits translate into a reduction in mortality or in the frequency with which patients require surgical drainage [23].

We conduct this study to try to clarify and illustrate the therapeutic effectiveness of intrapleurally-instilled purified streptokinase as an adjunct therapeutic agent for parapneumonic purulent pleural exudation cases, as compared to conventional surgical intervention; namely evacuation of pleural purulent exudation and decortication.

\section{Patients and Methods}

\section{Study design}

In this prospective comparable study initiated in the period between March 2016 and November 2018, sixty patients were admitted to Royal Commission Hospital (Western Province of KSA) and to other local hospitals (including Department of Cardiothoracic Surgery, Cairo University) in Egypt (47 males representing $78.33 \%$, and 13 females representing $21.66 \%$ ). Their age ranged from 18 to 60 years (mean 39.56 \pm 5.25 years). All of them were diagnosed having parapneumonic purulent pleural exudation. All of them were subjected to proper thoracostomy tube drainage with antibiotic coverage. Half of the patients (30 patients) (Group A patients) were offered the intrapleural administration of fibrinolytic therapy in which 250,000 IU streptokinase over $100 \mathrm{ml}$ normal saline was injected intrapleurally via the thoracostomy tube (once daily through six days duration). The other half of the patients (Group B patients) were offered conventional open surgical evacuation of purulent exudate and decortication.

\section{Inclusion and exclusion criteria}

The inclusion criteria for the study were the presence of pleural fluid that was macroscopically purulent, that was positive on culture for Gram's staining, and/or that had a $\mathrm{pH}$ below 7.2 in a patient with clinical evidence of infection. That was assessed by the recruiting physician on the basis of clinical parameters like fever, high white-cell count, and an elevated serum level of C-reactive protein. Excluded candidates were patients less than 20-years-old, patients with associated pleuro-pulmonary pathology e.g. existed bronchopleural fistula, lung abscess, and bronchiectasis, patients who experienced recent major multi-systems trauma, patients presenting with long-standing empyema, and patients with bilateral pleural effusions. Only patients with hematologic disorders, history of stroke, history of haemorrhage, on anticoagulant therapy, known sensitivity to streptokinase, or administered streptokinase during the past two years were offered only the option of surgical intervention (Group B patients).

\section{Management regimen}

Group (A) patients: Were offered closed thoracostomy tube insertion (using wide-bore intercostal chest tubes, sized $32 \mathrm{~F}$ to $36 \mathrm{~F}$ ) connected to a sterile underwater seal system with retrieval of pleural fluid samples for culture and sensitivity analysis. Confirmation of the proper positioning of the tube was always done immediately post-insertion by plain chest $\mathrm{X}$-ray. Empirical broad-spectrum antibiotics were initiated for a mean period of $91.5 \pm 36.4$ hours until results of culture of pleural sample were available, then, assumed antibiotic was administered. Daily output drainage was recorded. Administration of streptokinase started after 48 hours postinsertion of the properly-positioned chest tube with residual pleural space or pleural collection. 250,000 IU streptokinase over $100 \mathrm{ml}$ normal saline was administered intrapleurally through the chest tube once daily for 6 successive days. After administration, the tube was closed for 8 hours asking the patient to change posture to allow for good dissemination of the fibrinolytic agent through the pleural space, before reopening the tube again for the following 16 hours, then to repeat the procedure. Patients received various methods of chest physiotherapy both on-site and in-door. We continued this management pattern for a maximum of 6 days duration (total dose of 1,500,000 IU streptokinase) with radiologic follow-up every other day, meticulous recording of daily pleural drainage with observation of its nature and colour, and general vital signs clinical assessment. Haemorrhagic pleural output was a strict indication to abandon the procedure of streptokinase administration immediately with prompt stabilization of the general condition of the patient.

Group (B) patients: Were treated for the initial 48 hours as Group (A) patients, then they were shifted to operating room for open conventional drainage of residual pleural collection and decortication. They were then shifted to postoperative Intensive Care Unit (ICU) for close observation for a mean of $13.43 \pm 7.89$ hours, then to regular room followup radiologically every other day and meticulous recording of daily pleural drainage with observation of its nature and colour, and general vital signs clinical assessment. 


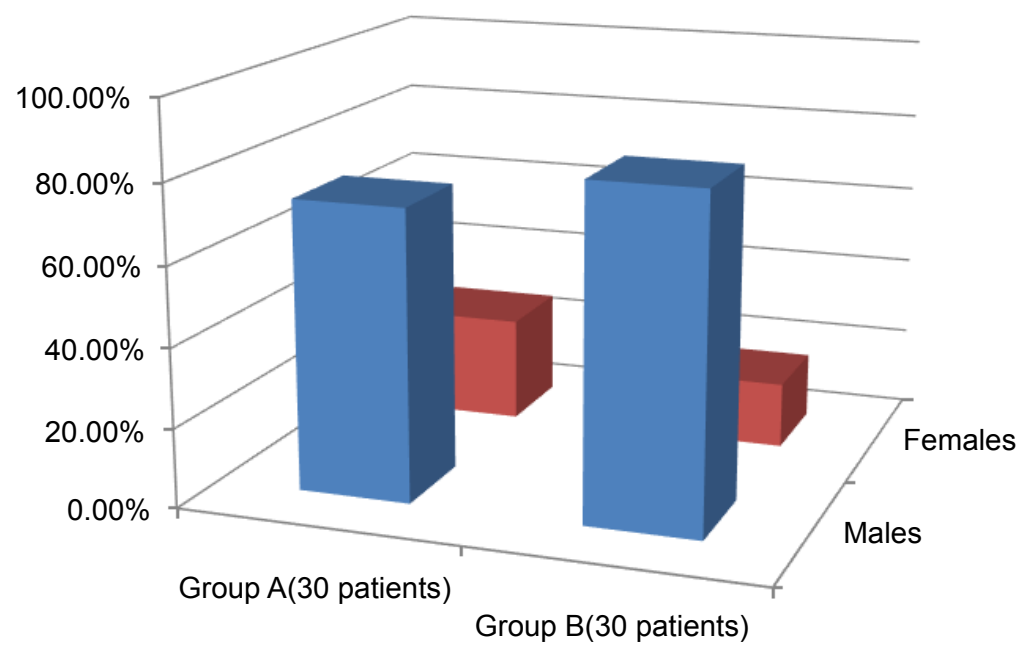

Figure 1: Distribution of patients based on sex.

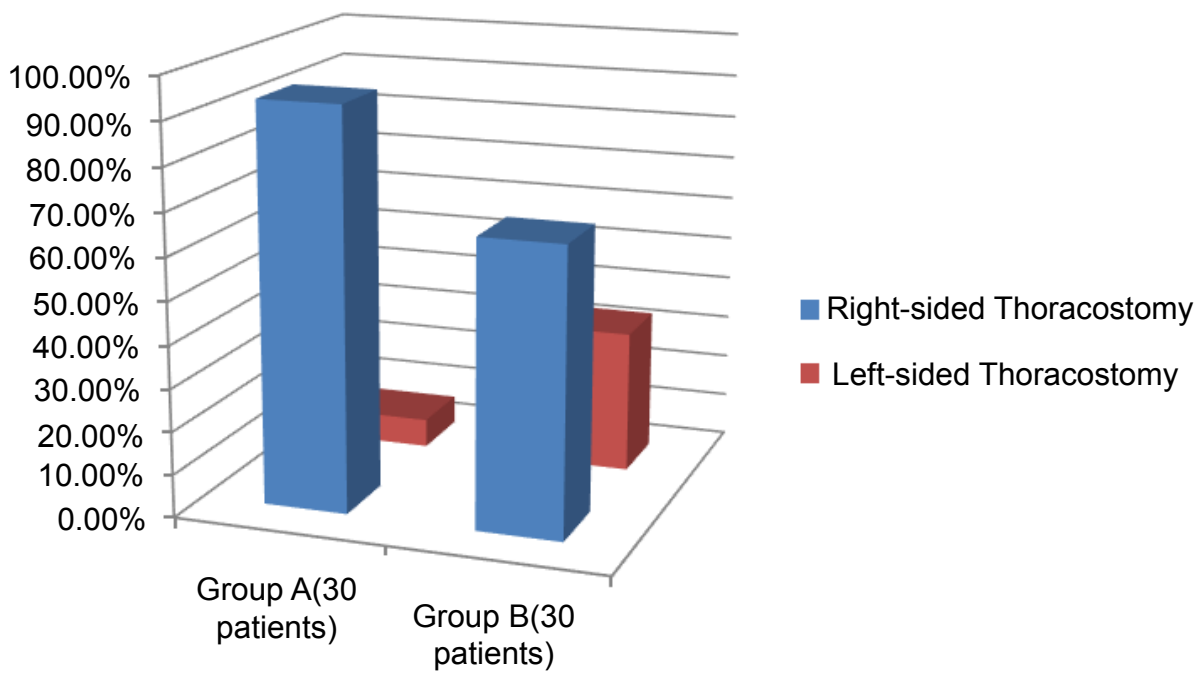

Figure 2: Thoracostomy tube side distribution in the study groups.

\section{Outcome endpoints}

We studied and compared the following outcome measures in both groups: Resolution of pleural exudation radiographically, relief of symptoms (fever, chest pain and tightness) and signs (high leucocytic count, high C-reactive protein), duration of total hospital stay (starting from inserting the chest tube drainage system until discharge from thoracic surgery point of view), mortality and other complications (intrapleural haemorrhage, persistent air leakage, persistent high pleural output, fever), and lastly, recurrence of the same condition at the same side of the chest within sixty days follow-up duration after discharge from thoracic surgery point of view.

\section{Results}

The study was conducted on a total of 60 patients. Their ages ranged from 18 to 60 years. The mean age was $39.56 \pm$ 5.25 years. For group $(A)$ patients, the mean age was $37.48 \pm$ 11.13 years and range was $20-56$ years. For group (B) patients, the mean age was $39.56 \pm 5.25$ years and range was $18-60$ years. 13 females and 47 males were studied. In group (A) patients, $26.66 \%$ were females and $73.33 \%$ were males while in group (B) patients, $16.66 \%$ were females and $83.33 \%$ were males (Figure 1).

All the patients were subjected to initial management in the form of thoracostomy tube drainage system and empirical broad-spectrum antibiotic (until the results of culture of the retrieved pleural sample were obtained, when an antibiotic was given accordingly). The mean duration prior to chest tube insertion in group (A) patients was $5.67 \pm 6.41$ days and in group (B) patients was $5.83 \pm 6.67$ days. Right-sided chest tubes were inserted in $93.33 \%$ of group (A) patients and in $66.66 \%$ of group (B) patients, while the remainders received left-sided chest tubes (based on the affected hemithorax). No patient in either group received bilateral chest tubes. The mean duration of empirical antibiotic given was $91.5 \pm 36.4$ hours in group (A) patients and $92.63 \pm 47.3$ hours in group (B) patients (Figure 2). 


\section{Group A(30 patients)}

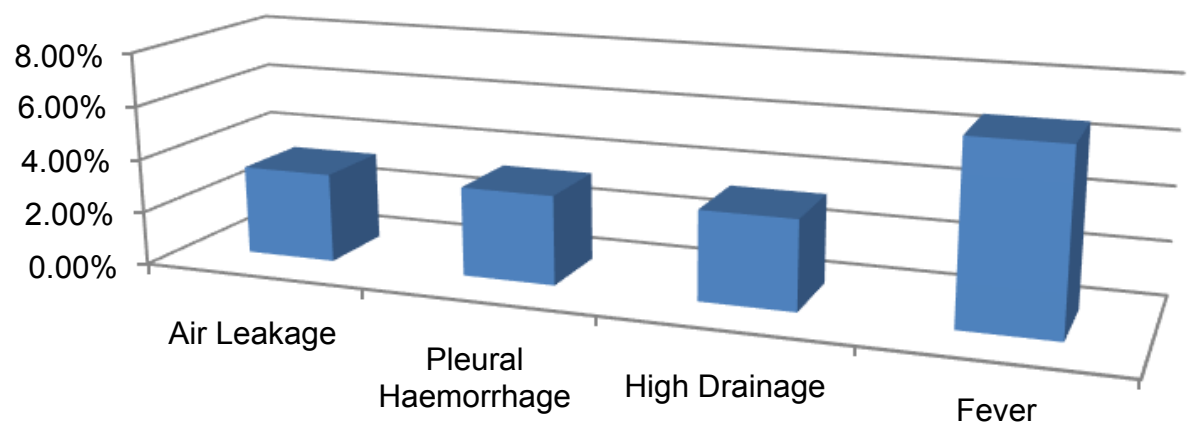

Figure 3: Adverse events in Group (A) population.

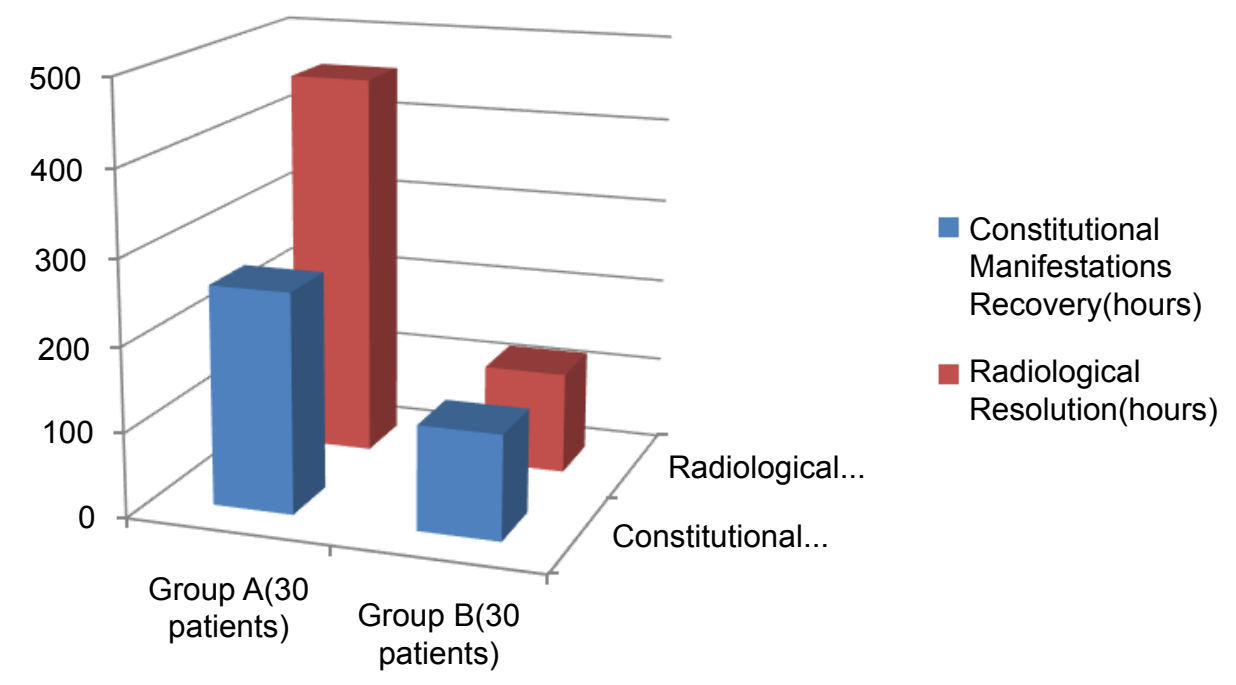

Figure 4: Recovery rates in the study groups.

During the first 48 hours after inserting the chest tube, the mean amount of pleural fluid drainage was $150.2 \pm 170.65$ $\mathrm{ml}$ in group (A) patients (range $50-320 \mathrm{ml}$ ) and $148.35 \pm$ $161.22 \mathrm{ml}$ in group (B) patients (range $50-300 \mathrm{ml}$ ). Thereafter, group (A) patients started to receive streptokinase injections intrapleurally through the chest tube once daily for 6 successive days. Group (B) patients were offered conventional open pleural fluid drainage and decortication followed by postoperative ICU stay. The mean duration of ICU stay was $13.43 \pm 7.89$ hours (range 4-28 hours).

In group (A) patients, there was no mortality and no one experienced hypersensitivity reaction following administration of streptokinase intrapleurally. One patient (3.33\%) developed air leakage after the third dose of streptokinase which was stopped and converted to thoracic surgery for decortication and leakage control. Another patient (3.33\%) showed intrapleural haemorrhage (evidenced in chest tube drainage and radiographic increase of pleural collection) after the third dose of streptokinase. For such patient, the protocol was abandoned and followed-up correcting his coagulation profile and the dropped haemoglobin level. Yet, he was not converted to thoracic surgery, but, experienced a long hospital stay period (33 days). One more patient (3.33\%) showed high daily pleural drainage output (with enhancing resolution of the pleural cavity radiographically) for which a long hospital stay was the result ( 26 days). A total of two patients (6.66\%) had fever (39-degree celsius) after the second dose of streptokinase administration. However, it was controlled, subsided and did not enforce us to discontinue the therapy in either of them (Figure 3).

In group (B) patients, no mortality happened. All the operations were eventless. They had a smooth eventless postoperative ICU course. One patient (3.33\%) faced delayed full lung inflation associated with low-grade fever (during in-ward stay) for him meticulous chest physiotherapy was applied. The rest of the group showed marked improvement of symptoms and signs of chest infection in a mean duration of $123.6 \pm 91.92$ hours (range 54-276 hours) while in group (A) patients, the mean duration was $259.2 \pm 108.35$ hours (range 93-487 hours). Coinciding with the relief of the constitutional manifestations was the resolution of pleural effusion radiologically where the mean duration was 120.53 
\pm 85.32 hours (range $50-240$ hours) in group (B) patients and $456.25 \pm 302.46$ hours (range 101-508 hours) in group (A) patients (Figure 4).

The mean duration of hospital stay for group $(A)$ patients starting from streptokinase administration until discharge from thoracic surgery point of view was $21.59 \pm 2.21$ days (range 8-33 days), while that for group (B) patients starting from decortication operation was $7.76 \pm 4.98$ days (range 4-12 days) including the period of the postoperative ICU stay until discharge from thoracic surgery point of view (Figure 5).

Patients of both groups were followed-up for the next sixty days following removal of chest tubes and discharge from thoracic surgery point of view (this discharge corresponded to the end of the studied hospital stay period concerning our procedure). There was no recurrence of the same condition on the same side during the follow-up period in the patients of both groups. The follow-up was conducted on clinical and radiological basis.

\section{Discussion}

This prospective comparable study represents a trial to clarify and judge the therapeutic efficacy and beneficial value of the fibrinolytic agent (streptokinase) compared to conventional open drainage and decortication in cases with parapneumonic purulent pleural effusion. This study demonstrates that intrapleural administration of streptokinase in such cases has longer period of hospital stay, relief of symptoms and subsidence of signs of chest infection, and resolution of pleural exudation radiologically. However, it does not affect mortality, but it carries higher risk of complications in terms of significant intrapleural haemorrhage and air leakage. These results come in favour with the 454-patients double-blind controlled trial by Nicholas, et al. which demonstrates that intrapleural streptokinase does not reduce mortality, the need for drainage surgery, or the duration of the hospital stay and does not improve outcomes as measured radiographically or by tests of lung function [24]. Patients who had open drainage and decortication through conventional thoracotomy in our study show quicker recovery, shorter hospital stay, better and faster resolution of pleural exudation and relief of annoying symptoms and signs of chest infection and are not subjected to the unpleasant complications of the intrapleurally administered streptokinase. The same findings are mentioned by Hilliard, et al. in their retrospective case note study of 48 children who emphasizes that early surgical management of empyema is associated with a favourable outcome [25]. Studies conducted before our trial have shown that streptokinase as a fibrinolytic agent does lead to macroscopically effective in vivo lysis of intrapleural fibrin adhesions and reduce the volume of infected pleural-fluid collections [13,26,27] Our study does not aim to readdress this question. We aimed to clearly clarify the value of using streptokinase compared to early thoracic surgery intervention to assess if streptokinase has already more impact on decreasing the hospital stay period, faster relief of constitutional manifestations of chest infection, quicker resolution of pleural opacification and cavity clearance, and to assess possible complications mentioned in the literature. However, in the study done by Ahmed AA, et al. [27] they illustrated that it seems likely if enzymatic therapy is initiated early in the evolution of an empyema- before fibrinopurulence is established and organization occurs with a well formed pleural peel becomes a reality- more extensive surgical procedures could be avoided (the mean duration before streptokinase installation is 3.45 days; compared to 5.67 \pm 6.41 days in our study) [27]. This seems to be a good parameter to judge which method of management might be chosen for a particular patient. Yet, fibrin deposition within the pleural cavity may take only a few days [28]. Thus, the definition of "early" might be obscure and patients may present early with multiloculated effusions which are not amenable to tube drainage obviating surgery. Moreover, there is a substantial systemic anti streptokinase-antibody response which might

\section{Mean Hospital Stay(days)}

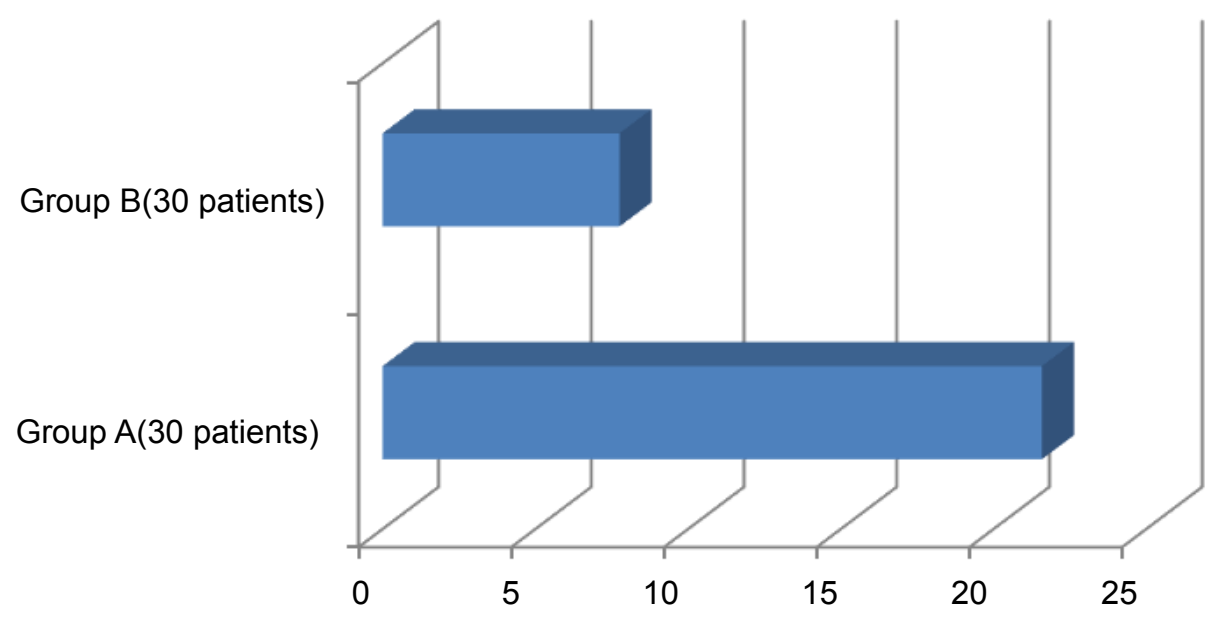

Figure 5: Mean duration of hospital stay. 
Citation: Saber A, Adel W (2019) Intrapleural Administration of Fibrinolytic Enzymes as an Adjunct Therapy of Parapneumonic Purulent Pleural Exudation: Does it Affect Outcome?. J Cardiothorac Surg Ther 3(1):24-30

inhibit the efficiency of streptokinase given later for a myocardial infarction or venous thromboembolism, thus, patients should then receive a different fibrinolytic agent [24]. This point, although it is not addressed in our study, adds to our belief that intrapleural fibrinolytic agents should be generally avoided, since they produce no advantage in either shortterm nor long-term outcomes, and do have some adverse effects. This was clearly evident in our study. We had one patient $(3.33 \%)$ developed air leakage after the third dose of streptokinase which was stopped, and thoracic surgery was then mandatory for decortication and air leakage control. Another patient (3.33\%) showed intrapleural haemorrhage (evidenced in chest tube drainage and radiographic increase of pleural collection) after the third dose of streptokinase. For such patient, the protocol was abandoned and followed-up correcting his coagulation profile and the dropped haemoglobin level. However, thoracic surgery was not addressed, and he experienced a long hospital stay period ( 33 days) receiving the traditional management of antibiotic coverage with chest tube drainage. One more patient $(3.33 \%)$ showed high daily pleural drainage output (with enhancing resolution of the pleural cavity radiographically) for which a long hospital stay was the result (26 days). A total of two patients (6.66\%) had fever (39-degree celsius) after the second dose of streptokinase administration. However, it was controlled, subsided and did not enforce us to discontinue the therapy in either of them. Occurrence of such adverse events namely; air leakage, intrapleural haemorrhage, high pleural drainage and fever supports and augments our conclusive results about the use of streptokinase intrapleurally.

In conclusion; it is obvious that definitive treatment of parapneumonic purulent pleural effusion is still debatable and multidisciplinary. This study represents a stepwise approach to this argument. Early open surgical management of parapneumonic purulent exudation is found to have a more favourable outcome than intrapleural administration of fibrinolytic enzymes which is found to have longer period of: Hospital admission, relief of symptoms and subsidence of signs of chest infection, resolution of pleural exudation, and carry higher risk of complications. However, it does not affect mortality. We were limited to have video-assisted thoracoscopic surgery (VATS) which achieve the best drainage in gross empyema or loculated effusions as well as open technique- because of its high cost and/or unavailability.

\section{References}

1. Ashbaugh DG (1991) Empyema thoracis: Factors influencing morbidity and mortality. Chest 99: 1162-1165.

2. Smith JA, Mullerworth MH, Westlake GW, et al. (1991) Empyema thoracis: 14-year experience in a teaching center. Ann Thorac Surg 51: 39-42.

3. Davies W, Kearney S, Gleeson F, et al. (2003) Predictors of outcome and long-term survival in patients with pleural infection. Am J Respir Crit Care Med 160: 1682-1686.

4. Idell S, Girard W, Koenig KB, et al. (1991) Abnormalities of pathways of fibrin turnover in the human pleural space. Am Rev Respir Dis 144: 187-194.
5. Strange C, Allen ML, Harley R, et al. (1993) Intrapleural streptokinase in experimental empyema. Am Rev Respir Dis 147: 962-966.

6. Sahn SA (1993) Management of complicated parapneumonic effusions. Am Rev Respir Dis 148: 813-817.

7. Tillett $W$, Sherry $S$ (1949) The effect in patients with streptococcal fibrinolysis (streptokinase) and streptococcal desoxyribonuclease on fibrinous, purulent, and sanguinous pleural exudations. J Clin Invest 28: 173-190.

8. Sahn SA (1998) Use of fibrinolytic agents in the management of complicated parapneumonic effusions and empyema. Thorax 53: S65-S72.

9. Chin NK, Lim TK (1997) Controlled trial of intrapleural streptokinase in the treatment of pleural empyema and complicated parapneumonic effusions. Chest 111: 275-279.

10. Lim TK, Chin NK (1999) Empirical treatment with fibrinolysis and early surgery reduces the duration of hospitalization in pleural sepsis. Eur Respir J 13: 514-518.

11. Coote N (2002) Surgical versus non-surgical management of pleural empyema: Cochrane review. In: The Cochrane library. Update Software, Oxford.

12. Cameron R, Davies H (2002) Intra-pleural fibrinolytic therapy for parapneumonic effusions and empyema. In: The Cochrane library. Update Software, Oxford.

13. Davies RJ, Traill ZC, Gleeson FV (1997) Randomised controllrd trial of intrapleural streptokinase in community acquired pleural infection. Thorax 52: 416-421.

14. Bouros D, Schiza S, Patsourakis G, et al. (1997) Intrapleural streptokinase versus urokinase in the treatment of complicated parapneumonic effusions: A prospective, double-bind study. Am J Respir Crit Care Med 155: 291-295.

15. Bouros D, Schiza S, Tzanakis N, et al. (1999) Intrapleural urokinase versus normal saline in the treatment of complicated parapneumonic effusions and empyema: A randomized, doubleblind stydy. Am J Respir Crit Care Med 159: 37-42.

16. Tuncozgur B, Ustunsoy $H$, Sivrikoz MC, et al. (2001) Intrpleural urokinase in the management of parapneumonic empyema: $A$ randomised controlled trial. Int J Clin Pract 55: 658-660.

17. Berglin E, Ekroth R, Teger-Nilsson AC, et al. (1981) Intrapleural instillation of streptokinase: Effects on systemic fibrinolysis. Thorac Cardiovasc Surg 29: 124-126.

18. Godley PJ, Bell RC (1984) Major haemorrhage following administration of intrapleural streptokinase. Chest 86: 486-487.

19. Davies CWH, Gleeson FV, Davies RJO (2003) BTS guidelines for the management of pleural infection. Thorax 58: 18-28.

20. Colice GL, Curtis A, Deslauriers J, et al. (2001) Medical and surgical treatment of parapneumonic effusions: an evidencebased guideline. Chest 119: 319.

21. Thomson AH, Hull J, Kumar MR, et al. (2002) Randomised trial of intrapleural urokinase in the treatment of childhood empyema. Thorax 57: 343-347.

22. Diacon AH, Theron J, Schuurmans MM, et al. (2004) Intrapleural streptokinase for empyema and complicated parapneumonic effusions. Am J Respir Crit Care Med 170: 49-53.

23. Lee YCG (2004) Ongoing search for effective intrapleural therapy for empyema: is streptokinase the answer? Am J Respir Crit Care Med 170: 1-2. 
Citation: Saber A, Adel W (2019) Intrapleural Administration of Fibrinolytic Enzymes as an Adjunct Therapy of Parapneumonic Purulent Pleural Exudation: Does it Affect Outcome?. J Cardiothorac Surg Ther 3(1):24-30

24. Nicholas AM, Christopher WH, Andrew JN, et al. (2005) UK controlled trial of intrapleural streptokinase for pleural infection. N Engl J Med 352: 865-874.

25. Hilliard TN, Henderson AJ, Langton Hewer SC (2003) Management of parapneumonic effusion and empyema. Arch Dis Child 88: 915-917.

26. Maskell NA, Davies RJO (2003) Effusions from parapneumonic infection and empyema. In: Light RW, Lee YCG, Textbook of pleural diseases. Arnold, London, 310-328.
27. Ahmed AA, Mohamed AR, Alaa EF, et al. (2011) Beneficial value of early utilization of intrapleural fibrinolytics in management of empyema thoracis and complicated post pneumonic effusion. Journal of The Egyptian Society of Cardio-Thoracic Surgery 19: 255-258.

28. Landay MJ, Christensen EE, Bynum LJ, et al. (1980) Anaerobic pleural and pulmonary infections. AJR Am J Roentgenol 134: 233-240. 